Original article

Paediatrics Today 2015;11(2):136-143

DOI $10.5457 / \mathrm{p} 2005-114.119$

\title{
THE SEASONAL DISTRIBUTION OF FEBRILE SEIZURES DOES NOT FOLLOW THE SEASONAL DISTRIBUTION OF FEBRILE ILLNESSES IN INFANTS AND TODDLERS
}

\author{
Smail ZUBČEVIĆ ${ }^{1 *}$, Tajma ĐELMO² \\ ${ }^{1}$ Pediatric Hospital, University Clinical \\ Center Sarajevo, Bosnia and Herzegovina \\ ${ }^{2}$ Klinikum Oberberg Kreiskrankenhaus \\ Gummersbach, Klinik für Neurologie \\ Deutschland
}

\footnotetext{
*Corresponding author: smail.zubcevic@gmail.com Tel.: + 38733566402

Fax.: +38733566525
}

Received: August 13, 2015

Accepted: September 3, 2015

Key words: Febrile seizures • Seasons - Infection.

\begin{abstract}
Objective - The aim of the study was to determine whether the febrile seizures occur more often in the cold period of the year (winter) when there are significantly more viral infections with fever in infants and toddlers, compared to the rest of the year. Patients and methods - A study was conducted at the Pediatric Clinic, University Clinical Centre in Sarajevo, and included all patients admitted for febrile seizures in two year period, 2011-2012. The data collected as possible predictors were: the time of the year when the febrile seizure was manifested, the season, and infectious causes of fever. Results - There were more male children, and the first febrile seizure occurred at an average age of $20.82 \pm 02.14$ months. The most common diagnosis for which the subjects were hospitalized was acute tonsillopharyngitis, and febrile illnesses with respiratory tract infections were present in $88.9 \%$ of children with febrile seizures. There was no statistically significant difference in the incidence of these diseases as an associated factor throughout the surveyed years, and no difference in the incidence of febrile seizures on a seasonal and monthly basis $\left(\chi^{2}=0.210 ; \mathrm{p}=0.976\right.$ and $\chi^{2}=0.658 ; \mathrm{p}=0.417$ respectively). Conclusion - The increased incidence of diseases with fever in young children in the winter months does not result in more frequent febrile seizures, which suggests that increased body temperature may not be the only factor which is linked to febrile seizures, and emphasizes genetic factors.
\end{abstract}

\section{Introduction}

Febrile seizures are the most common neurological disorder in childhood. They are defined as a seizure accompanied by fever (temperature $\geq 38^{\circ} \mathrm{C}$ by any method), without central nervous system infection, that occurs in infants and children from 6 to 60 months of age (1). The incidence differs around the world, from $2-5 \%$ in the USA in children of North American or European background to $6-9 \%$ of children in Japan (2). Simple febrile seizures are defined as brief $(<15$-minute) generalized seizures. Complex febrile seizures are prolonged ( $>15$ minutes), or focal, or occur more than once in 24 hours (1). About $70-80 \%$ children have only simple febrile seizures, and $20-25 \%$ have complex febrile seizures.

The underlying pathophysiology is not known. Febrile seizures tend to occur in families. When a child has febrile seizures, the risk of febrile seizure is $10 \%$ for a sibling and almost $50 \%$ for a sibling if a parent had febrile seizures as well. Although clear evidence 
exists for the genetic basis of febrile seizures, the mode of inheritance is unclear (3). Polygenic inheritance is thought to be prominent. However, in certain families, an autosomal dominant pattern of inheritance of febrile seizures has been identified. Some authors have described a "febrile seizure susceptibility trait" with an autosomal dominant pattern of inheritance with reduced penetrance. It is not clear whether the fever itself triggers febrile seizures, which some genetic studies are finding (4). The genes that are now connected with febrile seizures (like SCN1A, SCN2A, SCN1B, GABRG2 and GABRD) are those that encode the sodium channel and the gamma amino-butyric acid A receptor (5).

Febrile illnesses caused by viruses are very often associated with febrile seizures $(6,7)$. Various viruses are present in children with febrile seizures, and recent literature has indicated the presence of human herpes simplex virus 6 (HHSV-6) as the etiologic agent in roseola in about $20-30 \%$ of a group of patients presenting with their first febrile seizures (8). The influenza A virus has been seen in many children with recurrent febrile seizures (9). Gastroenteritis caused by Rotavirus doubles the odds of having febrile seizures, when compared with other viruses causing viral gastroenteritis. Gastroenteritis caused by Shigella is also associated with febrile seizures (10).

It has been proven that an increased risk of febrile seizures is present after immunization. Most studies showed a higher incidence of seizures after receiving the MMR (Measles, Mumps, Rubella) and DTPer (Diphtheria, Tetanus Pertussis) vaccines. Davis and Barlow demonstrated a four times higher risk of febrile seizures within 1-3 days of receiving the DTPer vaccine. After the MMR vaccination, the risk of febrile seizures increases between 1.5 and 3 times, where the occurrence of seizures peaked 1-2 weeks after vaccination (11). Similar results have been shown in more recent studies 12).
Viruses are the most common cause of febrile illnesses in children and seasonality is a long-recognized attribute of many viral infections in humans. The existing evidence suggests that the seasonality of some enteric and respiratory viral pathogens may be driven by the enhanced wintertime survival of pathogens, and also by increased host susceptibility resulting from relative "wintertime immune suppression" (13), it would be logical to assume that febrile seizures should have seasonal pattern in appearance.

This study tested the hypothesis that febrile seizures appear more frequently during the winter season.

\section{Materials and methods}

This cross-sectional study was carried out at the Pediatric Clinic of the University Clinical Centre in Sarajevo. The study included patients who were admitted to the Pediatric Clinic with the diagnosis of febrile seizures in a two-year period, 2011-2012. There were 210 children with febrile seizures in this period. All participants met the inclusion criteria for the study: aged 6 months to 5 years, diagnosis of febrile seizures, no clinical or other signs of infection of the central nervous system, and no previous seizures without febrile illness. No specific level of fever was required to diagnose febrile seizures. The data collected as possible predictors were: the time of the year when the febrile seizure was manifested, the season, and infectious causes of fever.

Children with seizures due to central nervous system infections (meningitis, encephalitis, meningoencephalitis), and children with a previous medical history of seizures without fever or epilepsy were excluded from our study. Outcome measure were febrile seizures. Upon completion of the survey, data were analyzed with standard statistical methods, using MS Excel (Microsoft Office Excel 2010) and SPSS for statistical analysis (Statis- 
tical Package for Social Sciences, SPSS Inc., Chicago, Illinois, USA), version 20.0.

\section{Ethics statement}

The survey was conducted in full compliance with the ethical requirements. The research was performed in accordance with the principles of good clinical practice and in accordance with the Helsinki Declaration and its recommendations for doctors who conduct biomedical research.

\section{Statistical analyses}

Basic demographic data are presented. We analyzed the arithmetic mean (X), standard deviation (SD) and standard error of arithmetic mean (SEM). For analysis of the results in normal distribution variables we used the parametric t-test, while the variables with skewed distribution were assessed by the nonparametric Mann-Whitney test. The $\chi^{2}$-test was used for non-quantitative variables. Values of $\mathrm{p}<0.05$ were taken as statistically significant.

\section{Results}

We studied a total of 210 children who were admitted to hospital in the given period. There were $118(56.2 \%)$ male and 92 (43.8\%) female children. The Chi-square test showed a statistically significant predominance of male children $\left(\chi^{2}=3.219 ; \mathrm{p}=0.047\right)$. The distribution of children admitted due to febrile seizures was similar on a yearly level (101 and 109).

The age range for the first febrile seizure was $20.82 \pm 14.02$ months. $21(10 \%)$ had a family history of febrile seizures, while 5 $(2.38 \%)$ had a family history of epilepsies.

Upon admission to hospital, the patients were treated for their febrile illness under different diagnosis, as shown in Table 1.
For 57 children no clear diagnosis of the febrile illness was established.

\begin{tabular}{|c|c|c|}
\hline Febrile illness & $\mathrm{n}$ & $\%$ \\
\hline Bronchitis acuta & 10 & 4.8 \\
\hline Gastroenterocolitis acuta & 10 & 4.8 \\
\hline Infectio tractus urinarii & 5 & 2.4 \\
\hline Status post vaccinationem & 2 & 1.0 \\
\hline Tonsillopharyngitis acuta & 123 & 58.6 \\
\hline Virosis & 3 & 1.4 \\
\hline Total & 153 & 72.9 \\
\hline No data & 57 & 27.1 \\
\hline Total & 210 & 100.0 \\
\hline
\end{tabular}

Incidence of the above diagnoses was investigated on a monthly level, and the results are shown in Table 2.

The Chi-square test did not find any significant difference in the incidence of febrile illnesses diagnosed monthly during one year, respiratory tract infections as the most common find in fever in children with febrile seizures had equal incidence in all months, and there was no statistically significant difference between the surveyed months $(p=0.09)$.

When we analyzed the frequency of different infections on a seasonal level (winter, spring, summer, autumn) we obtained the results shown in Table 3.

There was no statistically significant difference between the surveyed months $(\mathrm{p}=0.9)$. When we analyzed the frequency of febrile seizures on a seasonal level (winter, spring, summer, autumn) we obtained the results shown in Fig. 1. The Chi-square test showed no statistically significant difference in the incidence of febrile seizures in relation to seasons: $\chi^{2}=0.210 ; \mathrm{p}=0.976$.

Since we did not find any statistically significant difference in the incidence of febrile seizures, we wanted to see whether there were monthly differences. The results are shown in Tables 4 and 5 . 
Table 2 Incidence febrile illnesses that led to febrile seizures on a monthly level

\begin{tabular}{|c|c|c|c|c|c|}
\hline \multirow{3}{*}{ Months } & \multicolumn{4}{|l|}{ Febrile illnesses } & \multirow{2}{*}{ Total } \\
\hline & $\begin{array}{l}\text { Respiratory tract } \\
\text { infection }\end{array}$ & $\begin{array}{l}\text { Gastrointestinal tract } \\
\text { infection }\end{array}$ & Urinary tract infection & Postvaccinal seizures & \\
\hline & $\mathrm{n}(\%)$ & $\mathrm{n}(\%)$ & $\mathrm{n}(\%)$ & $\mathrm{n}(\%)$ & $\mathrm{n}(\%)$ \\
\hline Jan & $14(100)$ & - & - & - & $14(100)$ \\
\hline Feb & $10(90.9)$ & $1(9.1)$ & - & - & $11(100)$ \\
\hline Mart & $11(68.7)$ & $2(12.5)$ & $3(100)$ & - & $16(100)$ \\
\hline April & $12(73.3$ & $1(6.7)$ & $1(6.7)$ & $1(6.7)$ & $15(100)$ \\
\hline May & $7(100)$ & - & - & - & $7(100)$ \\
\hline June & $18(81.8)$ & $1(5.0)$ & $1(5.0)$ & - & $20(100)$ \\
\hline July & $22(90.9)$ & $1(4.5)$ & - & $1(4.5))$ & $22(100)$ \\
\hline Aug & $6(85.7)$ & $1(14.3)$ & - & - & $7(100)$ \\
\hline Sept & $7(87.5)$ & $1(12.5)$ & - & - & $8(100)$ \\
\hline Oct & 11 (84.6) & $2(15.4)$ & & & $13(100)$ \\
\hline Nov & $9(100)$ & - & - & - & $14(100)$ \\
\hline Dec & $11(100)$ & - & - & - & $11(100)$ \\
\hline Total & $136(88.9)$ & $10(6.5)$ & $5(3.3)$ & $2(1.3)$ & $153(100)$ \\
\hline
\end{tabular}

Table 3 Frequency of different infections causing fever in patients with febrile seizures on a seasonal level

\begin{tabular}{lllll}
\hline Season & Respiratory tract infection & Gastrointestinal tract infection & Urinary tract infection & Postvaccinal seizures \\
\hline Winter & 35 & 3 & 3 & 0 \\
Spring & 37 & 2 & 2 & 1 \\
Summer & 33 & 3 & 0 & 1 \\
Autumn & 31 & 2 & 0 & 0 \\
\hline Total & 136 & 10 & 5 & 2 \\
\hline
\end{tabular}
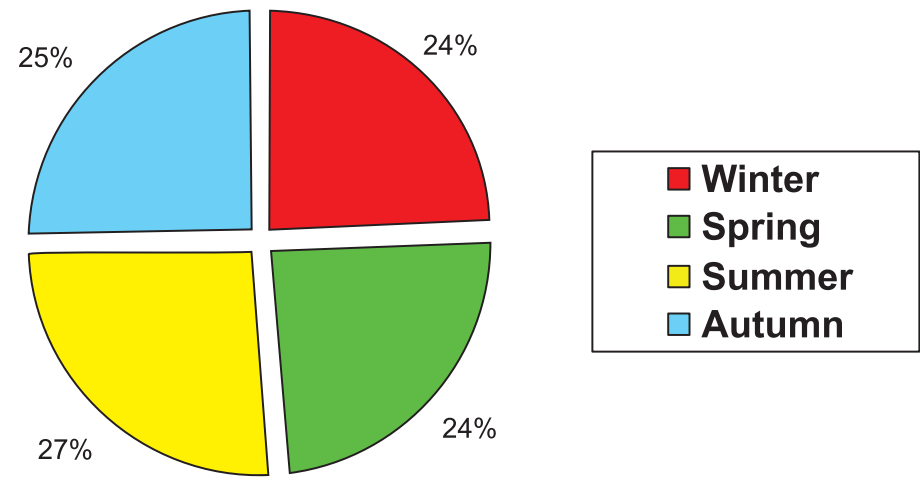

Fig. 1 Frequency of febrile seizures on a seasonal level.

The monthly incidence of febrile seizures in the surveyed period ranged from 4
$-14.9 \%$ in 2011 , and from $5.5 \%-12.8 \%$ in 2012. The months with the highest number 
Table 4 Monthly distribution of febrile seizures in 2011

\begin{tabular}{lllll}
\hline Months & $\mathrm{n}$ & $\%$ & Valid \% & Cumulative \% \\
\hline January & 6 & 5.9 & 5.9 & 5.9 \\
February & 5 & 5.0 & 5.0 & 10.9 \\
March & 16 & 15.8 & 15.8 & 26.7 \\
April & 10 & 9.9 & 9.9 & 36.6 \\
May & 5 & 5.0 & 5.0 & 41.6 \\
June & 11 & 10.9 & 10.9 & 52.5 \\
July & 15 & 14.9 & 14.9 & 67.3 \\
August & 5 & 5.0 & 5.0 & 72.3 \\
September & 4 & 4.0 & 4.0 & 76.2 \\
October & 7 & 6.9 & 6.9 & 83.2 \\
November & 9 & 8.9 & 8.9 & 92.1 \\
December & 8 & 7.9 & 7.9 & 100 \\
\hline Total & 101 & 1000 & 100 & - \\
\hline
\end{tabular}

of febrile seizures in 2011 were March, with $15.8 \%$ and July with $14.9 \%$, while in 2012 it was July with $12.8 \%$. The Chi-square test showed no statistically significant differences in the monthly incidence of febrile seizures: $\chi^{2}=0.658 ; p=0.417$.

\section{Discussion}

Since the seasonal occurrence of viral diseases has been well established, we wanted to find out whether febrile seizures follow the same pattern, or whether other factors are involved. Our study was the first assessment of this question in our population, since the previous large study of the clinical characteristics of the first febrile convulsions in children in Bosnia (14) did not address seasonal occurrence.

In our study almost $90 \%$ of children with an identified cause of their febrile illness had respiratory tract infection. Pathogens peak at characteristic times in all seasons of the year: winter: influenza, pneumococcus, rotavirus; spring: RSV, measles; summer: polio, other enteroviruses; fall: parainfluenza virus type 1 (15). In a study from Finland, cold temperature and low humidity were associated
Table 5 Monthly distribution of febrile seizures in 2012

\begin{tabular}{lllll}
\hline Months & $\mathrm{n}$ & $\%$ & Valid \% & Cumulative \% \\
\hline January & 10 & 9.2 & 9.2 & 9.2 \\
February & 8 & 7.3 & 7.3 & 16.5 \\
March & 6 & 5.5 & 5.5 & 22.0 \\
April & 7 & 6.4 & 6.4 & 28.4 \\
May & 8 & 7.3 & 7.3 & 35.8 \\
June & 10 & 9.2 & 9.2 & 45.0 \\
July & 14 & 12.8 & 12.8 & 57.8 \\
August & 8 & 7.3 & 7.3 & 65.1 \\
September & 9 & 8.3 & 8.3 & 73.4 \\
October & 10 & 9.2 & 9.2 & 82.6 \\
November & 10 & 9.2 & 9.2 & 91.7 \\
December & 9 & 8.3 & 8.3 & 100 \\
\hline Total & 109 & 100 & 100 & - \\
\hline
\end{tabular}

with the increased occurrence of respiratory tract infections, and a decrease in temperature and humidity preceded the onset of the infections (16). Since infections of the respiratory tract are the most common reason for febrile illness in small children, it would be expected that in colder months, during winter in Northern hemisphere, we should have more cases of febrile seizures. However in this study, in our sample we did not find any statistically significant seasonal difference in the incidence of diagnosis of respiratory tract infections among children with febrile seizures. The percentage of patients having a febrile illness with acute respiratory tract infection and febrile seizures varied from $68.7 \%$ in March (which is a winter month) to $100 \%$ in May (which is a spring month), but also in January (winter) and November (autumn). In fact, we had the highest incidence of respiratory infections among children with febrile seizures in the spring, but it was not statistically significant. It must also be noted that May and August were the months with the least febrile seizures. We also did not find any seasonal difference in the incidence of febrile seizures. They appeared quite uniformly dur- 
ing the four seasons in the two-year survey period.

Some studies in different parts of the world have shown a different trend. Mikkonen et al. (17), in his study of 461 children with febrile seizures, found that febrile seizures occurred irregularly throughout the year, most frequently in winter, concurrently with the febrile episodes, and least frequently in summer; this seasonal variation in the occurrence of febrile seizures disappeared, however, when adjusted for the number of febrile events. It is not clear whether this can be attributed to the increased occurrence of febrile seizures with the seasonal influenza vaccine, which was reported by WHO in 2014 (18), since children in Finland, unlike those in Bosnia, receive seasonal influenza vaccines. The seasonal occurrence of febrile seizures was also reported in Japan, in the NovemberJanuary period and in June-August (19), and in Italy in January (20).

Most of the studies on the epidemiology of febrile seizures, as well as child neurology textbooks, do not mention the seasonal occurrence of febrile seizures.

In discussing the different results from these studies and our data, we also looked to see whether a greater incidence of gastrointestinal (predominantly viral) infections can have an impact on the overall results, creating a balance between the colder and warmer seasons.

Enteroviruses (polioviruses, echoviruses, coxsackieviruses group A and group B, and enteroviruses) are responsible for significant and frequent human illness, including various neurological manifestations. The most common neurologic illness is aseptic meningitis. Encephalitis and other manifestations, such as paralysis, Guillain-Barré syndrome, transverse myelitis, cerebellar ataxia, and peripheral neuritis, also occur (21). For a long period of time, however, the association of enteroviral infection in the central nervous system (CNS) with febrile seizures has not been demonstrated, because the causative agent of the infection has not been detected in the CNS of patients with febrile seizures using standard techniques. Hosoya et al. (22) showed that the causative agents of febrile illness associated with seizures in the summer were primarily enteroviruses, especially the coxsackie viruses group $A$, and that febrile seizures might be caused by enteroviral infection in the central nervous system. But when we analyzed the percentage of patients with gastrointestinal infection and febrile seizures, we saw that it was only $5 \%-14 \%$ in the summer months, and the biphasic curve of the monthly incidence of febrile seizures seen in study by Hosoya et al. (22) was not seen in our study. Clearly, the more or less balanced diagnosis of acute respiratory tract infections throughout the year was linked to our results showing the rather uniform incidence of febrile seizures over the year. Besides this, the seasonal association of gastrointestinal infections with the incidence of febrile seizures was not shown to be a significant factor in our results.

All of this may suggest that increased body temperature as a result of infectious diseases is not the only factor linked to febrile seizures. The role of genetic factors is emphasized by the results of this study. It would be interesting to study the genetics of our patients regarding known genes for febrile seizures. Multiple factors are involved in the genesis of febrile seizures, and genetics may be responsible for their characteristics. In our study, the age range for the first febrile seizure was a little older, $20.82 \pm 14.02$ months, but generally within the expected range. Genetic susceptibility is present with a common family history of the condition, but in our study we obtained data about a positive family history in $10 \%$ of patients, which is rather low, but it must be considered in concordance with previous experience in history taking in 
children with neurological conditions in our population, where the parents are unwilling to discuss this issue.

We believe that it would be difficult to draw far stretching conclusions on this subject without large, multicentric studies, with a much greater number of children. The drawbacks of this observational study, as is the case for a large number of similar studies, were that, since it dealt with quite a benign condition, an insufficient number of microbiological studies have been undertaken in routine practice in these patients, and for majority of them the diagnosis of the febrile illness was made on clinical presentation. More precise virological and bacteriological findings would probably lead to a slightly different distributional picture of febrile seizures. Another shortcoming of this study was that it surveyed only a two-year period, and the epidemiological situation throughout that period need not be the same as it is over a longer period. Also, we would like to point out that we need more studies on the seasonal incidence of respiratory tract infections in our population, since the standard presumption that these are more common during the colder part of the year were not verified in this study.

\section{Conclusions}

Our study did not demonstrate any seasonal difference in the incidence of febrile seizures, as had been noted in some other studies. The increased incidence of diseases with fever in the winter months in young children was not associated with more frequent febrile seizures, which suggests that increased body temperature is only one of the complex factors that trigger febrile seizures.

Authors' contributions: Conception and design: ZS, TĐ; Acquisition, analysis and interpretation of data: TĐ, ZS; Drafting the article: ZS, TĐ; Revising it critically for important intellectual content: ZS, TĐ.
Conflict of interest: The authors declare that they have no conflict of interest.

\section{References}

1. Subcommittee on Febrile Seizures; American Academy of Pediatrics. Neurodiagnostic evaluation of the child with a simple febrile seizure. Pediatrics. 2011;127(2): 389-94.

2. Tsuboi T. Epidemiology of febrile and afebrile convulsions in children in Japan. Neurology. 1984; 34:175-81.

3. Audenaert D, Van Broeckhoven C, De Jonghe P. Genes and loci involved in febrile seizures and related epilepsy syndromes. Hum Mutat. 2006;27(5):391-401.

4. Kang JQ, Shen W, Macdonald RL. Why Does Fever Trigger Febrile Seizures? GABAA Receptor $\gamma^{2}$ Subunit Mutations Associated with Idiopathic Generalized Epilepsies Have TemperatureDependent Trafficking Deficiencies. J Neurosci. 2006;26(9):2590-7.

5. Nakayama J, Arinami T. Molecular genetics of febrile seizures. Epilepsy Res. 2006;70(Suppl 1):S190-8.

6. Wallace SJ, Zealley H. Neurological, Electroencephalographic, and Virological Findings in Febrile Children. Arch Dis Child. 1970;45(243):611-23.

7. Lewis HM, Parry JV, Parry RP, et al. Role of viruses in febrile convulsions. Arch Dis Child. 1979;54(11):869-76.

8. Millichap JG, Millichap JJ. Role of viral infections in the etiology of febrile seizures. Pediatr Neurol. 2006;35(3):165-72.

9. Kwong KL, Lam SY, Que TL, Wong SN. Influenza A and febrile seizures in childhood. Pediatr Neurol. 2006;35(6):395-9.

10. Doiron OA. Febrile Seizures: Controversy and Consensus. Can Fam Physician. 1983;29:94-7.

11. Davis RL, Barlow W. Placing the risk of seizures with pediatric vaccines in a clinical context. Paediatr Drugs. 2003;5(11):717-22.

12. Sun Y, Christensen J, Hviid A, Li J, Vedsted P, Olsen J, Vestergaard M. Risk of febrile seizures and epilepsy after vaccination with diphtheria, tetanus, acellular pertussis, inactivated poliovirus, and Haemophilus influenzae type B. JAMA. 2012;307(8):823-31. 
13. Fisman D. Seasonality of viral infections: mechanisms and unknowns. Clin Microbiol Infect. 2012;18(10):946-54.

14. Mustafić N, Tahirović H, Trnovčević J, Kapidzić A. Clinical characteristics at onset of first febrile convulsions. Acta Med Croatica. 2008;62(5):511-5

15. Dowell SF. Seasonal variation in host susceptibility and cycles of certain infectious diseases. Emerg Infect Dis. 2001;7(3):369-74.

16. Mäkinen TM, Juvonen R, Jokelainen J, Harju TH, Peitso A, Bloigu A, et al. Cold temperature and low humidity are associated with increased occurrence of respiratory tract infections. Respir Med. 2009;103(3):456-62.

17. Mikkonen K, Uhari M, Pokka T, Rantala H. Diurnal and seasonal occurrence of febrile seizures. Pediatr Neurol. 2015;52(4):424-7.
18. World Health Organization. Wkly Epidemiol Rec. 2014;89(7):53-60.

19. Tsuboi T, Okada S. Seasonal variation of febrile convulsion in Japan. Acta Neurol Scand. 1984;69(5):285-92.

20. Manfredini R, Vergine G, Boari B, Faggioli R, Borgna-Pignatti C. Circadian and seasonal variation of first febrile seizures. J Pediatr. 2004;145(6):838-9.

21. Cherry JD. Enteroviruses: coxsackieviruses, echoviruses, and polioviruses. In: Feigin RD, Cherry JD, eds. Textbook of Pediatric Infectious Diseases. 4th ed. Philadelphia, PA: WB Saunders Company; 1998:1787-1839.

22. Hosoya M, Sato M, Honzumi K, Katayose M, Kawasaki Y, Sakuma H, et al. Association of nonpolio enteroviral infection in the central nervous system of children with febrile seizures. Pediatrics. 2001;107(1):E12. 